\title{
Fabienne Moore, Prose Poems of the French Enlightenment. Delimiting genres
}

\section{Bianca Gai}

\section{Q OpenEdition}

1 Journals

\section{Edizione digitale}

URL: http://journals.openedition.org/studifrancesi/5941

DOI: 10.4000/studifrancesi.5941

ISSN: 2421-5856

\section{Editore}

Rosenberg \& Sellier

\section{Edizione cartacea}

Data di pubblicazione: 1 mai 2011

Paginazione: 167-168

ISSN: 0039-2944

\section{Notizia bibliografica digitale}

Bianca Gai, «Fabienne Moore, Prose Poems of the French Enlightenment. Delimiting genres», Studi

Francesi [Online], 163 (LV | I) | 2011, online dal 30 novembre 2015, consultato il 12 janvier 2021. URL: http://journals.openedition.org/studifrancesi/5941 ; DOI: https://doi.org/10.4000/studifrancesi.5941

Questo documento è stato generato automaticamente il 12 janvier 2021.

\section{(c) (i) (9)}

Studi Francesi è distribuita con Licenza Creative Commons Attribuzione - Non commerciale - Non opere derivate 4.0 Internazionale. 


\title{
Fabienne Moore, Prose Poems of the French Enlightenment. Delimiting genres
}

\author{
Bianca Gai
}

\section{NOTIZIA}

FABIENNE MOORE, Prose Poems of the French Enlightenment. Delimiting genres, Burlington, Ashgate, 2009, pp. 319.

1 Partendo dalla definizione di «poëme en prose» fornita nell'Encyclopédie da Jaucourt, il saggio analizza un genere lasciato talvolta in ombra dagli studi sulla letteratura settecentesca, apparentemente dominata dalla produzione in prosa. Fabienne Moore intende anticipare invece al xvIII secolo la nascita del genere, collocata abitualmente nel xix secolo romantico, così come la liberazione della scrittura poetica dai canoni formalistici del classicismo, verso una moderna concezione dell'ispirazione poetica come afflato interiore individuale. Se l'anticipazione della commistione setteottocentesca di prosa e poesia è stata talvolta rintracciata dai critici nella prosa poetica dell'llluminismo, lo studio rovescia la prospettiva rivalutando il binomio simmetrico della poesia in prosa. Dal volume emerge come la risposta alla domanda «comment être poète en prose?», che risale a un carnet di viaggio di Rous-seau, non si traduca in una ricerca puramente formale, ma sottintenda l'interrogativo più ampio-e carico di risonanze nella poesia a venire - in merito alla possibilità di essere insieme poeti $e$ moderni. Qualcosa dello spleen dei «petits poèmes en prose» baudelairiani è anticipato dallo sguardo degli autori settecenteschi qui esaminati. Sceglie la poesia in prosa Fénélon, il quale nelle Aventures de Télémaque (1699) se ne vale come mezzo per rivendicare insieme una libertà espressiva dai canoni estetici e un superamento dell'assolutismo politico. L'autrice esplora la modernità dell'opera feneloniana attraverso l'analisi del suo rifacimento pre-surrealista ad opera di Louis Aragon (1922), 
già evocato da Genette in Palimpsestes. Altra tappa fondamentale del genere è costituita da Le Temple de Gnide di Montesquieu (1725), la cui adesione alla struttura del «poème en prose» intende risolvere l'apparente incompatibilità tra il tema pastorale e il moderno. Nonostante il Settecento, a partire da Vico, abbia considerato la poesia la forma più adeguata al soggetto mitologico, perché più affine al linguaggio originario, la sua naturalità sembra contraddetta dal formalismo della poesia neoclassica. Costituisce un'efficace mediazione la poesia in prosa, in quanto contemporaneamente connessa alle radici poetiche della lingua e all'autenticità prosastica della modernità. Segue poi un capitolo su Le Lévite d'Ephraïm, in cui Rousseau ripercorre la storia della lingua umana, così come descritta nell'Essai sur l'origine des langues, mescolando prosa e poesia: alla narrazione della poesia d'amore del primo canto, modulata formalmente sul primitivismo della poesia delle origini, succedono i canti di argomento guerresco, in cui lo stile si adegua alla prosa dei tempi moderni. Conclude la trattazione l'esempio dell'Atala di Chateau-briand, in cui l'uso del genere è motivato dal tentativo di riprodurre il linguaggio selvaggio e la voce primitiva dei protagonisti. 